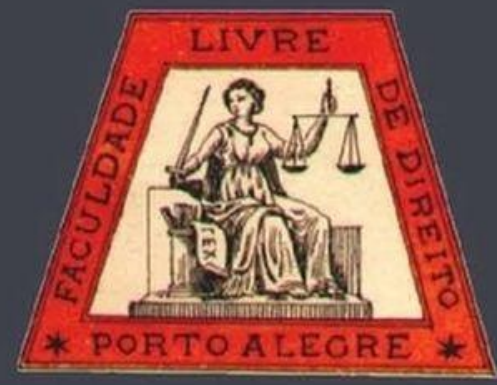

\title{
O controle da edição de medidas provisórias: avaliação legislativa da Emenda Constitucional no 32/2001
}

The control of the enactment of provisional measures: legislative evaluation of the Constitutional Amendment n 32/2001

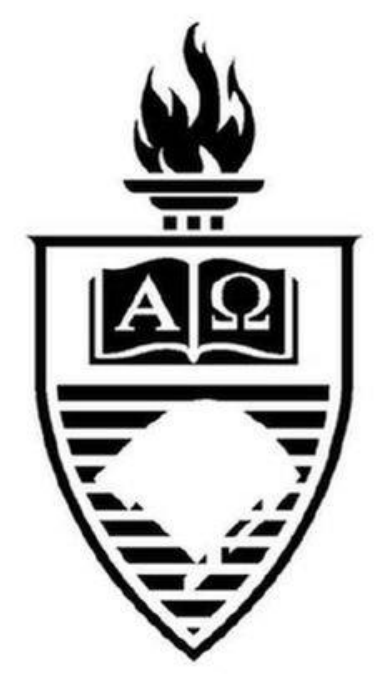

Murilo Gaspardo

Universidade Estadual Paulista

Mayara Paschoal Michéias

Universidade Estadual Paulista

\section{UFRGS}


O controle da edição de medidas provisórias: avaliação legislativa da Emenda Constitucional $\mathbf{n}^{0}$ $32 / 2001$

The control of the enactment of provisional measures: legislative evaluation of the Constitutional Amendment $n$ 32/2001

Murilo Gaspardo *

Mayara Paschoal Michéias **

\section{REFERÊNCIA}

GASPARDO, Murilo; MICHÉIAS, Mayara Paschoal. O controle da edição de medidas provisórias: avaliação legislativa da Emenda Constitucional n ${ }^{\circ}$ 32/2001. Revista da Faculdade de Direito da UFRGS, Porto Alegre, n. 39, vol. esp., p. 192-210, dez. 2018.

\section{RESUMO}

Trata-se de avaliação legislativa da Emenda Constitucional $n^{\circ} 32 / 2001$ com a finalidade de verificar sua eficácia. A partir da identificação prévia de seus objetivos, analisamos se os objetivos foram ou não atingidos, portanto, se a EC 32/2001 foi eficaz. A Emenda em questão foi elaborada para reformar a tramitação das medidas provisórias, as quais eram reeditadas constantemente. Por conseguinte, aprovou-se a Emenda Constitucional $\mathrm{n}^{\circ}$ 32/2001 com o objetivo de vedar as reedições de medidas provisórias e assim fortalecer o papel institucional do Congresso Nacional. Utilizamos o método da avaliação legislativa e a técnica da análise documental pertinente ao processo de elaboração da Emenda e à edição e apreciação de medidas provisórias pelo Congresso.

\section{PALAVRAS-CHAVE}

Medidas provisórias. Avaliação legislativa. Emenda Constitucional $\mathrm{n}^{\circ}$. 32/2001. Avaliação de eficácia. Separação de Poderes.

\section{ABSTRACT}

This study comprehends a legislative evaluation of the Constitutional Amendment n. 32/2001 in order to verify its effectiveness. Starting with a previous identification of the Amendment's objectives we analyze if its goals were achieved or not, therefore, if the Amendment was effective. This Amendment was approved to revise provisional measures' processing, which used to be re-edited very often. Therefore, the Constitutional Amendment n. 32/2001 was created to forbid the re-edition and reinforce the institutional role of the National Congress. We use the method of legislative evaluation and the documental analysis technique applied to documents related to the legislative process of the Amendment and the edition and assessment of provisional measures by Congress.

\section{KEYWORDS}

Provisional measures. Legislative evaluation. Constitutional Amendment n. 32/2001. Effectiveness evaluation. Separation of Powers.

\section{SUMÁRIO}

Introdução. 1. Medidas provisórias e a atuação normativa do Poder Executivo. 2. Emenda Constitucional No 32/2001. 3. A edição de Medidas Provisórias antes e depois da EC 32/2001. 4. Medidas provisórias e o trancamento de pautas. 5. Verificação da concretização dos objetivos da EC no atual panorama. Conclusão. Referências.

\section{INTRODUÇ̃̃̃}

A separação de Poderes clássica, entre Legislativo e Executivo, inspirada em
Montesquieu, foi concebida em um momento histórico determinado, em que o Estado apresentava atribuições mínimas e a grande

\footnotetext{
* Professor Assistente do Departamento de Direito Público da Universidade Estadual Paulista (UNESP). Doutor em Direito do Estado pela Universidade de São Paulo (2013).

** Graduada em Direito pela Universidade Estadual Paulista (UNESP).
} 
preocupação era a limitação de seu poder, para a garantia de direitos individuais.

Ocorre que, nas primeiras décadas do século $\mathrm{XX}$, o contexto socioeconômico passou a exigir um Estado mais forte e atuante, com novas atribuições. Nesse Estado intervencionista, o Poder Executivo passou a ter primazia, inclusive no campo da produção normativa, pois $\mathrm{o}$ Legislativo não estava preparado para atender a uma demanda legislativa mais numerosa e técnica.

No contexto anterior à Constituição Federal de 1988, o Brasil sofreu um período ditatorial em que essa superioridade do Executivo não teve quaisquer limitações, permitindo muitos abusos por parte dele. Um dos instrumentos que refletiam nessa situação era o decreto-lei, figura muito semelhante ao que temos hoje com as medidas provisórias.

Durante os debates constitucionais que culminaram na promulgação da Constituição Federal de 1988, como uma Constituição que visou reestruturar o país após um período ditatorial, muito se discutiu a respeito da instituição ou não das medidas provisórias, como instrumento que viria substituir o decreto-lei, pois o que se buscava nessa Constituição era limitar o Poder Executivo. A medida provisória tentou, a princípio, conciliar a efetividade (que era necessária para a garantia de políticas públicas) com a democracia, de forma que para que se transformasse em lei definitivamente seria necessário o aval do Legislativo, o que a tornava

\footnotetext{
${ }^{1}$ Os fundamentos da avaliação legislativa se encontram no "Guide to Evaluating Legislation" da Comissão Europeia, em que se propõe esta atividade como uma forma de trazer melhores soluções legislativas no futuro para eventuais situações que devam assim ser solucionadas. A avaliação se daria em função de três critérios básicos, que seriam: efetividade, que diz respeito a análise da conduta dos destinatários da norma legal com relação ao modelo normativo verificando se há correspondência; eficácia, que
}

um instrumento democrático sem perder a celeridade necessária, já que ela começaria a viger assim que publicada.

No Brasil, contudo, tal instrumento foi utilizado de forma indiscriminada por todos os Presidentes da República, desde o início da vigência da atual Constituição. Além de serem editadas excessivamente, por não haver, a priori, limites materiais, as medidas provisórias começaram a ser reeditadas constantemente para que, no decurso do prazo sem análise por parte do Legislativo, não perdessem sua eficácia.

Para tentar solucionar os problemas que envolviam as medidas provisórias, diversas PECs foram propostas, dentre as quais a PEC $n^{\circ}$ 472/1997, que apenas foi aprovada em 2001, convertendo-se na EC 32/2001, cujo principal objetivo era limitar a produção de medidas provisórias, mas, além disso, tivemos outras mudanças no sistema, como a instituição do sobrestamento de pautas. No entanto, ao analisar a doutrina e a situação política atual, vemos que ainda existem diversos problemas envolvendo as medidas provisórias.

Assim, tivemos por hipótese inicial que a Emenda Constitucional no 32/2001 não atingiu todos os seus objetivos, e que, em alguns pontos, como na instituição do trancamento de pautas, atingiu um resultado até mesmo inverso ao que almejava. Diante disso fizemos uma pesquisa de avaliação legislativa ${ }^{1}$ da Emenda Constitucional n 32/2001, sobretudo para verificar sua eficácia, se seus objetivos foram ou não atingidos.

diz respeito à análise se houve ou não atendimento da finalidade do legislador com a criação da norma; e eficiência, que compara investimentos com resultados, de forma que quanto maior o resultado e menor o investimento mais eficiente é a norma. Para recortar esta análise visando atingir os objetivos da pesquisa de acordo com os dados disponíveis, fizemos uma análise apenas da eficácia da emenda, de forma que consideramos quais foram os objetivos levantados na edição da emenda, e qual foi a realidade fática observada após sua edição. 
Destarte, buscamos responder às seguintes questões: (1) qual o contexto político ao à edição da EC 32/2001? Quais os seus objetivos? (2) Os objetivos da EC 32/2001 foram atingidos? (3) pode-se afirmar que as respostas adotadas pela EC foram as mais adequadas para a solução da problemática que a originou? Quais mudanças ainda podem ser feitas?

\section{MEDIDAS PROVISÓRIAS E A ATUAÇÃO NORMATIVA DO PODER EXECUTIVO}

Para compreender as medidas provisórias como manifestação da atuação normativa do Poder Executivo, necessário observar que tal atuação se mostra como um aspecto histórico no Brasil. O Poder Executivo sempre foi atuante, sobretudo no regime anterior. A Carta de 1967, alterada quase que em sua íntegra pela EC 01/1969, trazia o instrumento do decreto-lei, que garantia uma ampla e ilimitada atuação do Executivo na legislação.

Esse instrumento tem um histórico que nos remete ao surgimento da República, que se deu através de um Decreto. Também a alteração na ordem constitucional em 1930 foi feita mediante Decreto, e após esse momento "o governo passou a editar Decretos que abrangiam não somente assuntos do executivo como aqueles que seriam do legislativo". (MOTA DE SOUZA, 2003, p. 15) Ele esteve presente nas Constituições de 1937 e 1967, de modo que podemos apontá-lo como característico dos momentos autoritaristas da nossa história. $^{2}$

\footnotetext{
2"Não se pode perder de vista que o atual Estado Brasileiro teve como origem primeira a Monarquia. [...] Por isso, é comum verificar na história do Brasil a existência de atos do executivo com força de lei”. (MOTA DE SOUZA, 2003, p. 14)

3 “Art. 2 ${ }^{\circ}$. São Poderes da União, independentes e harmônicos entre si, o Legislativo, o Executivo e o Judiciário". (BRASIL, 1988)
}

Em razão desse histórico, a Constituição de 1988 teve certa cautela quando da atribuição de poderes atípicos ao Executivo, com o propósito de evitar que abusos voltassem a ocorrer. Observe-se que apesar do estabelecimento da separação de Poderes em seu art. $2^{\circ}$, tais atribuições atípicas se faziam necessárias para garantir que os inúmeros direitos e garantias estabelecidos ao longo dos artigos da CF/88 fossem efetivados.

Assim, a Constituição Federal de 1988 estabeleceu instrumentos à disposição do Presidente da República que, apesar de garantirem sua atuação, deveriam passar pelo crivo do Poder Legislativo, com o fim de evitar abusos, como é o caso das medidas provisórias. ${ }^{4}$ Consequentemente, passou a ser necessária uma grande cooperação entre os Poderes Executivo e Legislativo.

O decreto-lei, ao ser promulgado, tinha imediato status de lei, podendo o Congresso aprová-lo ou recusá-lo em sua íntegra, e, não o fazendo, ocorria aprovação tácita do texto, que se converteria em lei imediatamente.

Em sentido oposto, desde sua criação original, as medidas provisórias apenas se converteriam em lei se fossem aprovadas pelo Congresso, ou seja, ante a não análise teríamos uma rejeição tácita.

Em especial, o fato de ser o antigo decretolei aprovado tacitamente quando o Legislativo não o analisava no prazo previsto, fazia com que, ao editar inúmeros decretos, o Executivo conseguisse a aprovação de todos eles, o que demonstrava um déficit democrático em sua elaboração, já que o Legislativo sequer

\footnotetext{
4 "Seu acolhimento na qualidade de instrumento normativo primário à disposição do Presidente da República resultou de intensos debates, nos quais se evidenciou uma preocupação central: o novo instituto, proscrita a aprovação por decurso de prazo, seria diverso do decreto-lei." (CRUZ, 2017, p.25)
} 
participava da análise e o dispositivo tornava-se lei.

A medida provisória tentou, a princípio, conciliar essa efetividade com a democracia, de forma que, para que se transformasse em lei, seria necessário o aval do Legislativo, o que a tornaria um instrumento democrático sem perder a celeridade necessária, já que ela começaria a viger assim que publicada, mas apenas se tornaria lei se aprovada pelo Congresso. ${ }^{5}$

Magali Carvalho Alves de Oliveira (2009, p. 46-47) destaca que o surgimento das medidas provisórias se deu principalmente para conciliar a governabilidade com a democracia, de forma que dotou o Executivo de instrumento que seria ágil, mas passível de ser utilizado apenas em situações de emergência, além da ocorrência da fiscalização pelo Legislativo.

Apesar de preocupado em se distanciar do decreto-lei, como forma de proteção à democracia, o constituinte não se preocupou em limitar as matérias sujeitas ao tratamento por meio de medidas provisórias, apenas estabelecendo limites circunstanciais que seriam a relevância e a urgência, conceitos abertos que também não se preocupou em definir. E, em razão disso, desde o início da vigência da atual Constituição, esse foi utilizado de forma indiscriminada por todos os Presidentes da República.

\footnotetext{
5 "O argumento é o seguinte: no mundo moderno, o governo é chamado a desempenhar múltiplas e crescentes funções, pois cada vez mais se vê confrontado com situações imprevisíveis em que é preciso agir de forma rápida e ágil. Assim, para evitar as crises motivadas pela incapacidade de ação do governo e para impedir que ele se veja paralisado por conflitos internos, cumpre dotar o Executivo de poderes legislativos excepcionais. Além disso, nos países latinoamericanos, em especial o Brasil, com sistemas partidários fragmentados e de fraca disciplina interna, é por intermédio desses poderes que o Executivo pode aumentar a capacidade de implementar uma agenda de governo." (FIGUEIREDO; LIMONGI, 2001, p.125)

${ }^{6}$ Nos anos de 1994 e 2001, observa Amaral Júnior (2004, p. 204-208), o número de medidas provisórias (consideradas
}

Além de serem editadas em números consideravelmente altos (pois próximos ao das Leis Ordinárias) ${ }^{6}$, por não haver a priori limites materiais, as medidas provisórias eram reeditadas (o que ocorreu por permissão do próprio Legislativo) constantemente para que, no decurso do prazo sem análise por parte do Legislativo, não perdessem sua eficácia.

Com a reedição, perdeu-se a intenção do constituinte de diferenciar a medida provisória do decreto-lei por meio da necessária participação do Legislativo antes de se converter em lei, visto que, reeditando sucessivamente uma medida não analisada no prazo, teria ela não só a força de lei, mas também teria a vigência da lei, ou seja, por tempo indeterminado.

Também era problemática a questão da revogação de normas anteriores pelas medidas provisórias, que se somava à reedição. Apesar de muitas discussões, chegou-se ao posicionamento de que as medidas provisórias revogavam normas a elas contrárias com condição resolutiva ${ }^{7}$. No entanto, ante a recorrente prática da reedição, surgia uma situação de insegurança jurídica prolongada no tempo, pois, se após inúmeras reedições uma medida provisória fosse revogada, tal situação teria efeitos ex tunc, o que causaria a repristinação daquela norma que teria sido por ela substituída por longo intervalo, como já apontado.

as reedições) teria superado o número de leis ordinárias editadas. Ademais, comparando com o número de reiteração de decretos-legges, instituto italiano que teria inspirado o surgimento das medidas provisórias em nosso ordenamento, o número de reedições de medidas provisórias no Brasil se mostrou superior.

${ }^{7}$ Neste sentido, destacou Amaral Júnior (2004, p. 132): "Ora, se a medida provisória é lei (ao menos materialmente), efetivamente revoga a legislação anterior com ela conflitante, anda que o faça sob condição resolutiva, qual seja, a conversão em lei. Nesta linha seguem a jurisprudência do Supremo Tribunal Federal, bem como as doutrinas italiana e espanhola." 
Quando considerada a perda de efeitos da revogação tácita sob o ângulo das sucessivas e indeterminadas reedições, a insegurança jurídica ficava majorada, pois uma norma, vigente por longo prazo, era vigente por tempo indeterminado, e poderia ser revogada tacitamente com efeitos ex tunc, com efeitos retroativos para atingir todas as relações que foram por ela disciplinadas.

Outro ponto que devemos destacar, é que, havendo tantas reedições, ficou demonstrada a inércia do Legislativo que não atuava como deveria no controle da atividade normativa do Presidente da República. O instituto foi desvirtuado, e o órgão que deveria realizar o controle político de sua utilização nada fazia.

Existia um verdadeiro controle da agenda do Legislativo por parte do Executivo, que editava, revogava e reeditava medidas, moldando a atuação do Congresso Nacional conforme seus interesses. Por vezes abarrotava sua agenda com medidas provisórias de assuntos desprovidos de qualquer relevância, para evitar que fossem votados determinados assuntos e em outros momentos revogavam outras medidas para garantir que algum assunto de seu interesse fosse deliberado.

As medidas, dentre outros aspectos, fizeram com que nosso governo se constituísse, conforme Argelina Figueiredo e Fernando Limongi (1999, p.23), com especificidades tais que seu sistema (constituído pelo multipartidarismo associado ao

\footnotetext{
9 "A nosso ver, os efeitos dos poderes legislativos presidenciais são de outra natureza. Eles determinam o poder de agenda do chefe do Executivo, entendendo-se por agenda a capacidade de determinar não só que propostas serão consideradas pelo Congresso, mas também quando o serão. Maior poder de agenda implica, portanto, a capacidade do Executivo de influir diretamente nos trabalhos legislativos e assim minorar os efeitos da separação dos poderes, o que pode induzir os parlamentares à cooperação”. (LIMONGI e FIGUEIREDO, 1999, p. 23)
}

presidencialismo) resultasse no chamado presidencialismo de coalizão, que seria a forma encontrada para a cooperação entre Executivo e Legislativo se dar de forma efetiva. ${ }^{8}$

Esse sistema, denominado presidencialismo de coalizão, se caracterizaria pelas vastas funções atípicas de legislar atribuídas ao Presidente da República, sobretudo as medidas provisórias, o que afetaria as relações entre Executivo e Legislativo, tendo em vista o poder de agenda que essas prerrogativas conferem ao Presidente sobre o Congresso. Deste modo, pode o Presidente, graças a esse poder, determinar quais propostas serão objeto de consideração do Congresso e quando o serão. ${ }^{9}$

Isso teria ocorrido, segundo Abranches (1988, p.19), em razão de nosso sistema, apesar de presidencialista, ter adotado o multipartidarismo, diferentemente da experiência norte-americana, de forma que o estabelecimento de coalizões se mostrou indispensável à atuação estatal. ${ }^{10}$ Esse sistema, contudo, poderia levar a diversas instabilidades na presidência.

Assim, nesse contexto, a medida provisória levou à reanálise da separação de Poderes ${ }^{11}$ e ao surgimento de novas teorias, como a de Figueiredo e Limongi, na qual se estuda o presidencialismo de coalizão sob a luz do poder de agenda do Executivo sobre o Legislativo, que, para eles teria sido concedido pelas medidas provisórias:

\footnotetext{
10 "A grande maioria (76\%: 13/17) dos regimes liberaisdemocráticos do após-guerra é parlamentarista. (...)É também aí que se revela a natureza do regime até agora praticado no Brasil. Não existe, nas liberais-democracias mais estáveis, um só exemplo de associação entre representação proporcional, multipartidarismo e presidencialismo.” (ABRANCHES, 1988, P.19)

${ }^{11}$ Importante observar que, “a 'separação dos Poderes' da Constituição brasileira prevê a medida provisória não como um elemento de sua própria desestabilização ou derrogação, mas como elemento que a integra e dá feição." (AMARAL
} JÚNIOR, 2004, p. 302) 
Um presidente dotado de amplos poderes legislativos é capaz de ditar a agenda de trabalhos legislativos e, dessa forma, induzir parlamentares à cooperação. Conta ainda com recursos não legislativos advindos do controle que exerce sobre o acesso aos postos de governo. (FIGUEIREDO; LIMONGI, 1999, p.26)

Tínhamos, portanto, o problema da ausência de limites materiais, que foi um retrocesso até mesmo se comparado ao decretolei, que tinha limites definidos; tínhamos a questão da relevância e urgência, requisitos extremamente indeterminados que eram analisados sem qualquer técnica pelas Comissões Mistas ${ }^{12}$; além do problema do prazo muito curto para análise das medidas provisórias, que andava lado a lado às reedições.

Essa situação deixava o Congresso Nacional insatisfeito, e esse contexto ensejou o surgimento de diversas PECs $^{13}$, como forma de buscar a solução para os diversos problemas existentes. Apesar de não se tratar de assunto com a "maior" prioridade na agenda do Congresso, surgiu uma busca pela mudança.

Dentre as diversas PECs propostas, temos a Proposta de Emenda à Constituição nº 472/1997 que resultou na aprovação da Emenda Constitucional 32/2001, foco de nossa avaliação legislativa.

\section{EMENDA CONSTITUCIONAL N³2/2001}

Para que seja possível a avaliação legislativa sob o enfoque da eficácia devemos primeiro identificar seus objetivos. Esses objetivos, conforme Salinas (2008, p. 38), “não precisam estar necessariamente previstos na própria norma, podendo ser identificados no preâmbulo de uma lei, na exposição de motivos do projeto legislativo ou até mesmo nos debates parlamentares antecedentes a sua votação".

Assim, iniciamos a análise com o próprio histórico do texto normativo analisado. Seu surgimento se deu diante dos diversos problemas causados pelas medidas provisórias, buscando solucionar parte dos problemas. A Proposta de Emenda Constitucional 472/1997, que resultou na EC 32/2001 foi originária do Senado Federal sob o n. 1/95 e surgiu em um contexto em que várias outras propostas eram feitas em ambas as Casas do Congresso Nacional.

O cenário era de muitas discussões e muita pressão para que a situação mudasse. $\mathrm{O}$ abuso do instrumento legislativo das medidas provisórias por parte dos Presidentes da República incomodava não só a população, de uma forma geral, mas especialmente os parlamentares, que, como foi possível observar ao longo das discussões, sentiam a ameaça à Separação de Poderes, como se destaca no trecho a seguir, na fala do Senador Josaphat Marinho:

13 “Na Câmara dos Deputados, foram apresentadas 6 (seis) propostas: PEC n. 2/95 (BRASIL, 1995e), n. 8/95(BRASIL, 1995k), n. 13/95(BRASIL, 1995c), n. 18/95(BRASIL, 1995d), n. 26/95(BRASIL, 1995g) e n. 52/95(BRASIL, 1995i), sendo que a PEC n. 8/95, a PEC n. 13/95, a PEC n. 18/95, a PEC n. 26/95 e a PEC n. 52/95 foram apensadas à primeira, a PEC n. 2/95 que, por sua vez, foi apensada à PEC n. 472/97(BRASIL, 1997a)." (MORITSUGU SILVA, 2013, p. 38)

\footnotetext{
12 "Para a constituição dessas Comissões Mistas, a Resolução n. 1/89 do Congresso Nacional (BRASIL, 1989b) dispôs que as lideranças partidárias indicariam, a cada nova medida provisória editada, parlamentares para a integrarem. Possibilitava-se, com esse fato, que se constituísse uma Comissão somente com parlamentares que tivessem interesses outros, seja por fazerem parte da base governista ou por incentivos decorrentes do fisiologismo, que não fossem a análise estritamente técnica dos pressupostos formais de relevância e urgência." (MORITSUGU SILVA, 2013, p. 35)
} 
No entanto, a aplicação de medidas provisórias vem sendo rotineiramente desvirtuadas ao serem editadas sem nenhuma relevância e urgência. Diante desse quadro, não seria exagero afirmar que o Executivo está usurpando a função legislativa do Poder competente representado pelo Congresso Nacional. (CÂMARA DOS DEPUTADOS, Dossiê digitalizado da PEC 472/1997, p. 31).

Na justificação da proposta é demonstrado um contexto de grande produção de medidas provisórias e, principalmente, de um considerável número de reedições. Essa prática colocava em xeque a segurança jurídica, além de manter abarrotada a agenda do Congresso Nacional, de modo que eram, por essa razão, em muitos casos, usadas como estratégia do Presidente para controlar indiretamente a atuação do Legislativo.

Outra situação que se apontava era o uso das medidas provisórias de forma indiscriminada no que diz respeito aos tributos, prática que desrespeitava diversos princípios constitucionais tributários. Notava-se que o Executivo aproveitava a situação de "inércia" dos outros Poderes para atuar como quisesse.

Ademais, notava-se que urgência e relevância, por serem pressupostos extremamente amplos, não eram respeitadas pelo Presidente ao editar medidas provisórias. O principal motivo de preocupação, contudo, era a falta de limites materiais para as medidas provisórias. Antes da EC 32/2001 era possível editar medidas provisórias sobre praticamente qualquer matéria, o que, somado a reedição, resultava no abuso do instituto.

Assim, realizada uma análise cuidadosa das discussões e pareceres, obtidos no dossiê digitalizado da PEC 472/1997 ${ }^{14}$, e também do texto final da EC 32, seriam os objetivos do legislador: (a) Proteger a segurança jurídica, por meio da limitação à produção de medidas

14 Trata-se da compilação de todos os documentos discutidos na PEC em questão, solicitado em: provisórias acerca de algumas matérias mais sensíveis, como direito penal, direito processual ou nacionalidade, mas também com a vedação as reedições na mesma sessão legislativa, além da determinação de como se disciplinariam as relações jurídicas diante da revogação de uma medida provisória; (b) Restaurar o equilíbrio entre os Poderes, com a limitação da atuação do Presidente da República na edição de medidas provisórias, o que se revelou na proibição de edição de medidas acerca da organização do Judiciário e do Ministério Público, mas também na busca da garantia ao Parlamento do exercício de suas prerrogativas e atribuições, atribuindo-se maior prazo para a análise; (c) Reduzir a produção de medidas provisórias, que consideravam excessiva, por meio da vedação da edição de medidas provisórias acerca de diversos assuntos elencados no art. 62; (d) Restaurar a atuação do Executivo no processo legislativo ordinário, com projetos de lei, o que ficou revelado na justificação da PEC, como algo esperado ao se disciplinar as medidas provisórias; (e) Ampliar o prazo de análise das medidas provisórias pelo Congresso, bem como instituir o regime de urgência, de forma a garantir sua participação na elaboração das mesmas, para fazer com que a revogação tácita de medidas provisórias fosse cenário excepcional.

Devidamente elencados os objetivos da Emenda Constitucional, passamos à verificação da concretização destes, de modo a concluir se a EC 32/2001 foi ou não eficaz no controle da produção de medidas provisórias.

<http://www.camara.gov.br/proposicoesWeb/fichadetramit acao?idProposicao=14784>. 


\section{A EDIÇÃO DE MEDIDAS PROVISÓRIAS ANTES E DEPOIS DA EC 32/2001}

Analisamos a quantidade de medidas editadas e reeditadas ${ }^{15}$, bem como quantas delas se tornaram leis, foram rejeitadas, ou perderam a eficácia pela rejeição tácita, com decurso do prazo. Com esses dados, pudemos elencar os seguintes objetivos da EC 32/2001: (1) redução da produção de medidas provisórias; e (2) restauração da participação do Congresso no processo de análise, para evitar a rejeição tácita.

No quadro 1 temos os dados relativos ao período 1988-2001 (antes da EC 32/2001), o que constitui o parâmetro de comparação para $o$ período registrado no quadro 2 (posterior à EC 32/2001). Quanto aos status, verificamos as convertidas em leis, rejeitadas ou revogadas e as que perderam eficácia, utilizando os parâmetros de pesquisa já disponíveis no site da Câmara dos Deputados.

Quadro 1:

\begin{tabular}{|l|l|l|l|l|l|l|}
\hline \multicolumn{6}{|c|}{ MEDIDAS PROVISORIAS ANTES DA EMENDA CONSTITUCIONAL 32/2001 } \\
\hline Ano & Edições & Reedições & Total & $\begin{array}{l}\text { Convertidas } \\
\text { em Lei }\end{array}$ & $\begin{array}{l}\text { Rejeitadas e/ou } \\
\text { Revogadas }\end{array}$ & $\begin{array}{l}\text { Perda de } \\
\text { eficácia }\end{array}$ \\
\hline 1988 & 15 & 9 & 24 & 11 & 1 & 3 \\
\hline 1989 & 93 & 10 & 103 & 81 & 9 & 3 \\
\hline 1990 & 93 & 70 & 163 & 72 & 10 & 4 \\
\hline 1991 & 9 & 2 & 11 & 7 & 2 & 1 \\
\hline 1992 & 7 & 3 & 10 & 7 & 1 & - \\
\hline 1993 & 47 & 49 & 96 & 26 & 2 & 4 \\
\hline 1994 & 91 & 314 & 405 & 41 & 4 & 6 \\
\hline 1995 & 32 & 405 & 437 & 42 & 18 & 6 \\
\hline 1996 & 34 & 615 & 649 & 15 & 15 & - \\
\hline 1997 & 40 & 680 & 720 & 32 & 11 & - \\
\hline 1998 & 53 & 750 & 803 & 44 & 62 & \\
\hline 1999 & 47 & 1040 & 1087 & 37 & 40 & 1 \\
\hline 2000 & 23 & 1088 & 1112 & 16 & 17 & - \\
\hline 2001 & 13 & 478 & 491 & 45 & 68 & - \\
\hline
\end{tabular}

Fonte: Elaboração própria com dados disponíveis em <http://www2.camara.leg.br/atividade-

legislativa/legislacao> Acesso em: 03 set. 2017.
Como observamos no quadro acima, o contexto inicial era de edição de um grande número de medidas provisórias, vide os anos de 1989 e 1990, e, posteriormente, com a possibilidade de reedições, também um grande número de medidas reeditadas, como ocorreu, sobretudo, em 1999 e 2000.

Notamos, ainda, que o número de medidas que perderam a eficácia era consideravelmente pequeno, não ultrapassando $6 \mathrm{em}$ nenhum dos anos analisados. O número de medidas rejeitadas ou revogadas também se mostrou pequeno, tendo certo aumento apenas a partir do ano de 1998, momento de discussão da PEC 472/97, em ocorreu uma retomada da participação do Congresso no âmbito das discussões das medidas provisórias.

A fim de comparar estes dados, temos o Quadro 2.

Quadro 2:

\begin{tabular}{|l|l|l|l|l|}
\hline \multicolumn{5}{|c|}{ MEDIDAS PROVISÓRIAS APÓS A EC N ${ }^{\circ} 32 / 2001$} \\
\hline Ano & Edições & Convertidas em lei & $\begin{array}{l}\text { Rejeitadas e/ou } \\
\text { Revogadas }\end{array}$ & $\begin{array}{l}\text { Perda de } \\
\text { eficácia }\end{array}$ \\
\hline 2001 & 20 & 18 & - & - \\
\hline 2002 & 82 & 66 & 15 & 1 \\
\hline 2003 & 58 & 57 & 1 & - \\
\hline 2004 & 73 & 66 & 5 & 3 \\
\hline 2005 & 42 & 34 & 6 & 2 \\
\hline 2006 & 67 & 60 & 3 & 4 \\
\hline 2007 & 70 & 60 & 8 & 2 \\
\hline 2008 & 40 & 35 & 4 & 1 \\
\hline 2009 & 27 & 24 & - & 3 \\
\hline 2010 & 42 & 30 & 2 & 10 \\
\hline 2011 & 36 & 29 & 1 & 6 \\
\hline 2012 & 45 & 38 & - & 7 \\
\hline 2013 & 35 & 27 & - & 8 \\
\hline 2014 & 29 & 15 & 1 & 14 \\
\hline 2015 & 43 & 34 & - & 7 \\
\hline 2016 & 56 & 38 & - & 13 \\
\hline 2017 & 33 & 3 & - & 2 \\
\hline
\end{tabular}

Fonte: Elaboração própria com dados obtidos em<http://www2.camara.leg.br/atividade-

legislativa/legislacao> Acesso em: 03 set. 2017.

A partir de 2001, não temos mais as reedições, as quais foram vedadas pela EC 32/2001. Entretanto, quanto à edição de Medias Provisórias, notamos que os números são muito

forma de nova medida provisória, apenas buscavam prolongar no tempo os efeitos de medida provisória anterior. 
semelhantes aos anteriores à EC, o que pode ser melhor verificado no gráfico abaixo:

\section{Gráfico 1:}

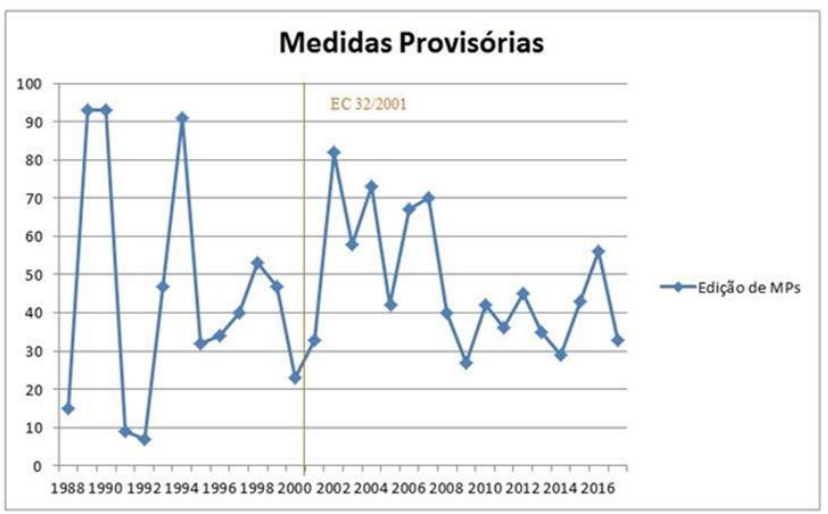

Fonte: Elaboração própria com dados obtidos em<http://www2.camara.leg.br/atividade-

legislativa/legislacao> Acesso em: 03 set. 2017.

Notamos que, embora alguns anos tenham se destacado com números realmente elevados de medidas provisórias editadas, o que pode ser atribuído às diferentes políticas adotadas pelos Governos, de uma forma geral não se alterou muito o parâmetro após a EC. Não observamos uma queda em razão da EC (como era esperado), pelo contrário, no ano de 2002 foram editadas 82 medidas provisórias.

A variação do número de medidas convertidas em lei é ilustrada pelo gráfico seguinte:

Gráfico 2:

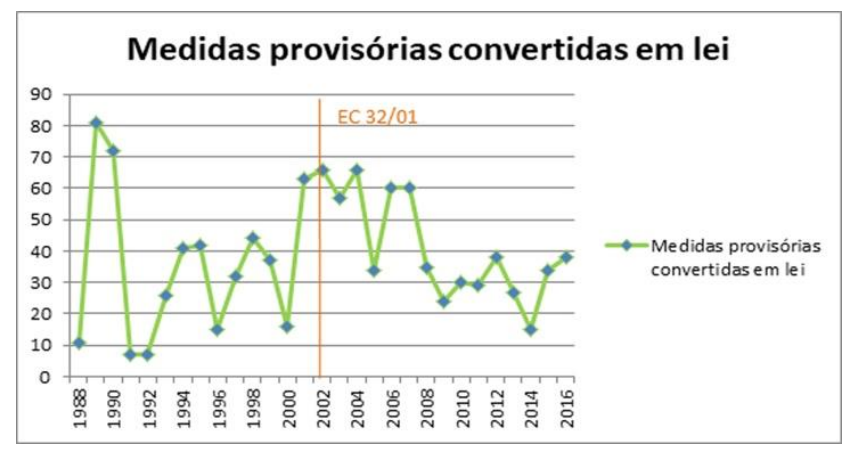

Fonte: Elaboração própria com dados obtidos em<http://www2.camara.leg.br/atividadelegislativa/legislacao> Acesso em: 03 set. 2017.
No gráfico 2 nota-se que no momento logo após a emenda o número de medidas convertidas em lei aumentou, mas posteriormente sofreu uma redução.

Quanto ao número de medidas que perderam a eficácia, temos o gráfico 3 , também elaborado com os dados dos quadros:

\section{Gráfico 3:}

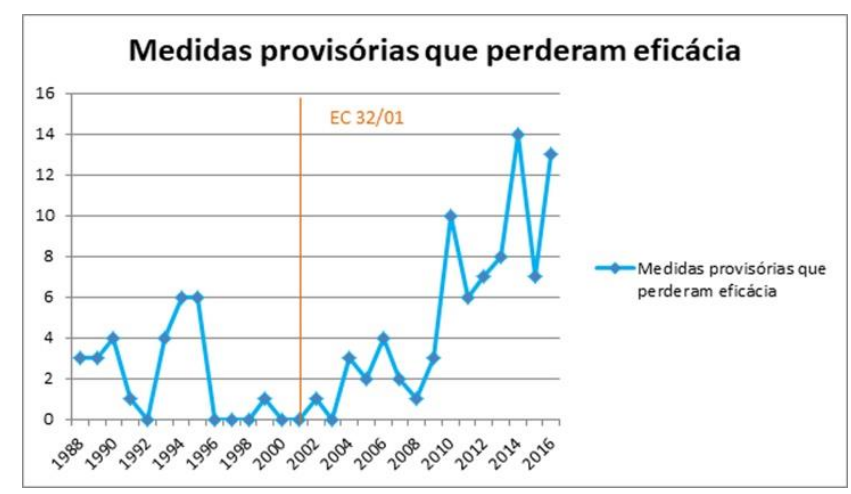

Fonte: Elaboração própria com dados obtidos em $<$ http://www2.camara.leg.br/atividade-

legislativa/legislacao> Acesso em: 03 set. 2017.

Neste gráfico, notamos claramente um aumento do número de medidas que perderam a eficácia, ou seja, foram rejeitadas tacitamente, sem a análise do Congresso.

É importante ainda contextualizar os números de medidas provisórias produzidas, convertidas em lei e que perderam sua eficácia em face da produção de leis ordinárias no mesmo período: 
Quadro 3:

\begin{tabular}{|l|l|l|l|}
\hline Ano & Leis Ordinárias & MPs (Re)editadas & MPS convertidas em lei \\
\hline 1988 & 68 & 24 & 11 \\
\hline 1989 & 276 & 103 & 81 \\
\hline 1990 & 166 & 163 & 72 \\
\hline 1991 & 238 & 11 & 7 \\
\hline 1992 & 222 & 10 & 7 \\
\hline 1993 & 225 & 96 & 26 \\
\hline 1994 & 131 & 405 & 41 \\
\hline 1995 & 281 & 437 & 42 \\
\hline 1996 & 177 & 649 & 15 \\
\hline 1997 & 169 & 720 & 32 \\
\hline 1998 & 178 & 803 & 44 \\
\hline 1999 & 175 & 1087 & 37 \\
\hline 2000 & 218 & 1112 & 16 \\
\hline 2001 & 230 & 511 & 63 \\
\hline 2002 & 237 & 82 & 66 \\
\hline 2003 & 197 & 58 & 57 \\
\hline 2004 & 252 & 73 & 66 \\
\hline 2005 & 176 & 42 & 34 \\
\hline 2006 & 178 & 67 & 60 \\
\hline 2007 & 198 & 70 & 60 \\
\hline 2008 & 259 & 40 & 35 \\
\hline 2009 & 290 & 27 & 24 \\
\hline 2010 & 191 & 42 & 30 \\
\hline 2011 & 208 & 36 & 29 \\
\hline 2012 & 193 & 45 & 38 \\
\hline 2013 & 172 & 35 & 27 \\
\hline 2014 & 129 & 29 & 34 \\
\hline 2015 & 163 & 43 & 38 \\
\hline 2016 & 171 & 56 & 3 \\
\hline 2017 & 65 & 33 & \\
\hline & & & 13 \\
\hline
\end{tabular}

Fonte: Elaboração própria com dados disponíveis em $<$ http://www2.camara.leg.br/atividade-

legislativa/legislacao> Acesso em: 03 set. 2017.

Verificamos que o número de MPs produzidas (editadas e reeditadas) em alguns anos superou o número de leis ordinárias editadas (vide anos 1994 a 2001). Com a EC 32/2001, o fim da reedição mudou esse quadro, de modo que, apesar de o número de leis ordinárias produzidas não ter se alterado de forma considerável, o número de medidas provisórias editadas sequer atingiu 50\% daquele. Para melhor visualizar esse fato, temos o Gráfico 4.
Gráfico 4:

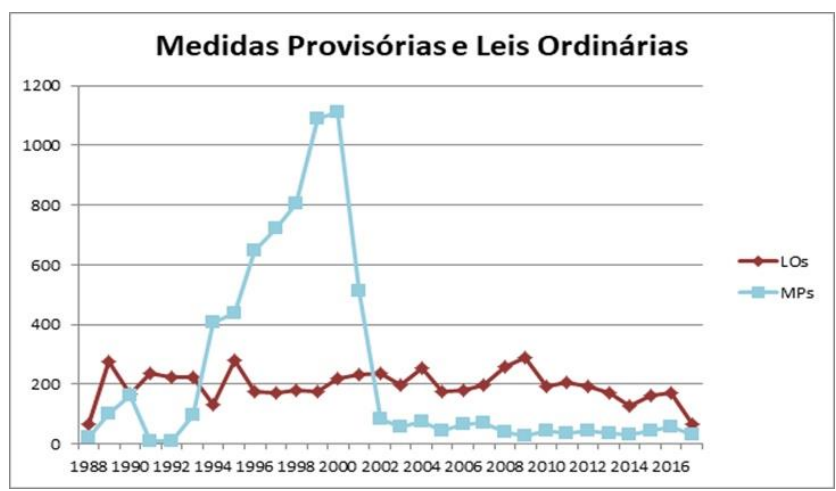

Fonte: Elaboração própria com dados obtidos em<http://www2.camara.leg.br/atividade-

legislativa/legislacao> Acesso em: 03 set. 2017.

Outro aspecto que destacamos na análise foi a quantidade de leis ordinárias produzidas a partir de projetos de lei do Poder Executivo, em razão de termos identificado nas discussões que levaram à EC 32/2001 uma intenção de fazer com que o Poder Executivo voltasse a atuar na atividade legislativa também por esse modo.

Para demonstrar essa análise, elaboramos o seguinte quadro, em que relacionamos a quantidade de leis ordinárias editadas por ano no total, a quantidade de MPs convertidas em lei, e a quantidade de leis que foram originárias de Projeto de Lei do Poder Executivo, o que fica também demonstrado através de porcentagem. 
Quadro 4:

\begin{tabular}{|l|l|l|l|l|}
\hline Ano & Leis Ordinárias & $\begin{array}{l}\text { MPS } \\
\text { convertidas } \\
\text { em lei }\end{array}$ & $\begin{array}{l}\text { Leis Criadas a } \\
\text { partir de PL do } \\
\text { Executivo }\end{array}$ & $\begin{array}{l}\text { Leis } \\
\text { decorrentes de PL } \\
\text { do Executivo }\end{array}$ \\
\hline 1988 & 68 & 11 & 20 & 29,41 \\
\hline 1989 & 276 & 81 & 27 & 9,78 \\
\hline 1990 & 166 & 72 & 21 & 12,65 \\
\hline 1991 & 238 & 7 & 54 & 22,69 \\
\hline 1992 & 222 & 7 & 25 & 11,26 \\
\hline 1993 & 225 & 26 & 53 & 23,56 \\
\hline 1994 & 131 & 41 & 24 & 18,32 \\
\hline 1995 & 281 & 42 & 30 & 10,68 \\
\hline 1996 & 177 & 15 & 35 & 19,77 \\
\hline 1997 & 169 & 32 & 24 & 14,20 \\
\hline 1998 & 178 & 44 & 21 & 11,80 \\
\hline 1999 & 175 & 37 & 20 & 11,43 \\
\hline 2000 & 218 & 16 & 28 & 12,84 \\
\hline 2001 & 230 & 63 & 26 & 11,30 \\
\hline 2002 & 237 & 66 & 29 & 12,24 \\
\hline 2003 & 197 & 57 & 25 & 12,69 \\
\hline 2004 & 252 & 66 & 20 & 7,94 \\
\hline 2005 & 176 & 34 & 28 & 15,91 \\
\hline 2006 & 178 & 60 & 22 & 12,36 \\
\hline 2007 & 198 & 60 & 16 & 8,08 \\
\hline 2008 & 259 & 35 & 25 & 9,65 \\
\hline 2009 & 290 & 24 & 27 & 9,31 \\
\hline 2010 & 191 & 30 & 38 & 19,90 \\
\hline 2011 & 208 & 29 & 15 & 7,21 \\
\hline 2012 & 193 & 38 & 24 & 12,44 \\
\hline 2013 & 172 & 27 & 27 & 15,70 \\
\hline 2014 & 129 & 15 & 16 & 12,40 \\
\hline 2015 & 163 & 34 & 10 & 6,14 \\
\hline 2016 & 171 & 38 & 10 & 5,85 \\
\hline 2017 & 65 & 3 & 4 & 6,15 \\
\hline & & & & \\
\hline
\end{tabular}

Fonte: Elaboração própria com dados obtidos em<http://www2.camara.leg.br/atividade-

legislativa/legislacao> Acesso em: 03 set. 2017.

Esses números, analisados em comparação com o número total de leis ordinárias, nos permitiu elaborar o seguinte gráfico:

Gráfico 5:

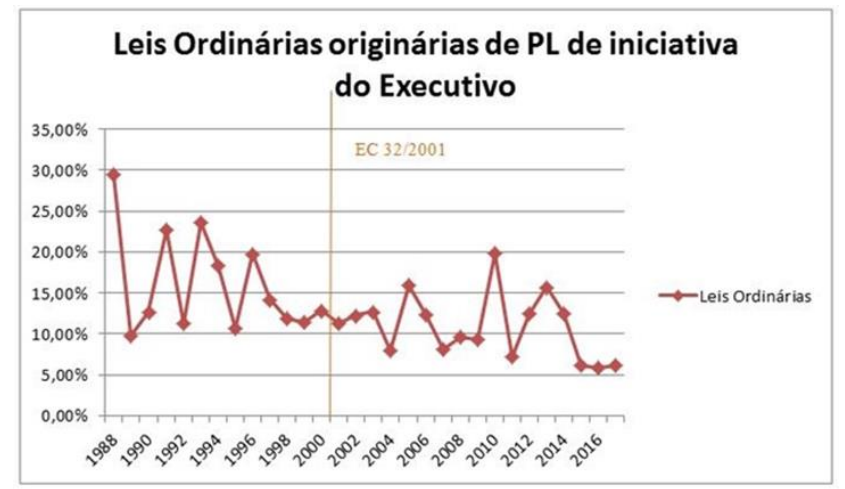

Fonte: Elaboração própria com dados obtidos em<http://www2.camara.leg.br/atividade-

legislativa/legislacao> Acesso em: 03 set. 2017.

Como verificamos ao analisar o gráfico, embora o objetivo do Congresso fosse aumentar a atuação do Executivo no processo legislativo por meio de projetos de lei, não notamos um aumento significante dessa atuação após a EC. Pelo contrário, notamos que os números oscilam, mas, de uma forma geral, são baixos se analisados à luz da produção de medidas provisórias, que ainda se mostram como meio mais fácil e rápido do Presidente atuar no processo legislativo.

Outro importante aspecto que estudamos foi o trancamento de pautas, instituído pela EC 32/2001.

\section{MEDIDAS PROVISÓRIAS E O TRANCAMENTO DE PAUTAS}

Como ressaltamos, um dos objetivos da EC 32/01 foi o restabelecimento do equilíbrio entre Executivo e Legislativo. Nesse sentido, instituiuse o sobrestamento de pautas com um aparente intuito de garantir que as medidas provisórias fossem analisadas pelo Congresso, para assim evitar a perda de eficácia com rejeição tácita.

Para analisar qual foi o impacto dessa mudança e concluir como ficou a relação entre Executivo e Legislativo, buscamos dados estatísticos acerca do sobrestamento de pautas, os quais foram solicitados à Câmara dos Deputados através do seu instrumento de atendimento à população. Em resposta à solicitação nos disponibilizaram um estudo realizado pela Secretaria Geral da Mesa, em 09/01/2015, com base no período 2001-2014.

No entanto, foi feita a ressalva de que tal estudo não fora verificado ou publicado. Apesar da ressalva, como nossa pesquisa não será baseada exclusivamente nessas informações disponibilizadas, decidimos utilizá-las. Assim, elaboramos o seguinte quadro com os dados respectivos, que nos demonstram a quantidade de pautas trancadas por medidas provisórias no período 2001-2014, além da relação percentual. 
Quadro 5:

\begin{tabular}{|l|l|l|l|}
\hline \multicolumn{3}{|c|}{ PAUTAS TRANCADAS POR MEDIDAS PROVISORIAS 2001-2014 } \\
\hline Ano & Total de Pautas & Pautas obstruídas por MPs & $\begin{array}{l}\text { Porcentagem de pautas } \\
\text { obstruídas por MPs }\end{array}$ \\
\hline 2001 & 103 & 1 & $0,97 \%$ \\
\hline 2002 & 75 & 48 & $64 \%$ \\
\hline 2003 & 170 & 74 & $43,53 \%$ \\
\hline 2004 & 145 & 103 & $71,03 \%$ \\
\hline 2005 & 150 & 113 & $75,33 \%$ \\
\hline 2006 & 140 & 92 & $65,71 \%$ \\
\hline 2007 & 193 & 124 & $64,25 \%$ \\
\hline 2008 & 162 & 90 & $55,56 \%$ \\
\hline 2009 & 175 & 97 & $55,43 \%$ \\
\hline 2010 & 123 & 61 & $49,59 \%$ \\
\hline 2011 & 169 & 97 & $57,40 \%$ \\
\hline 2012 & 160 & 75 & $46,88 \%$ \\
\hline 2013 & 217 & 67 & $30,88 \%$ \\
\hline 2014 & 156 & 48 & $30,77 \%$ \\
\hline
\end{tabular}

Fonte: Elaboração própria com dados obtidos em<http://www2.camara.leg.br/atividade-

legislativa/legislacao> Acesso em: 03 set. 2017.

Gráfico 6:

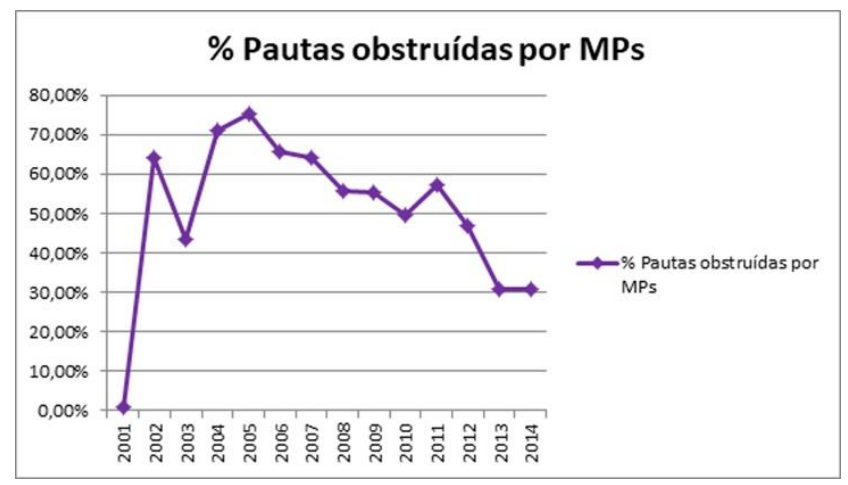

Fonte: Elaboração própria com dados obtidos em<http://www2.camara.leg.br/atividade-

legislativa/legislacao> Acesso em: 03 set. 2017.

Entre 2001 e 2014, em média 50,81\% das pautas foram trancadas por medidas provisórias, número consideravelmente elevado. $\mathrm{O}$ mínimo entre 2002 e 2014 de pautas trancadas por medidas provisórias foi de $30,77 \%$.

Tais dados nos permitem concluir que o sobrestamento de pautas não foi uma mudança qualquer no trâmite das medidas provisórias e merece atenção.

\section{VERIFICAÇÃO DA CONCRETIZAÇÃO DOS OBJETIVOS DA EC NO ATUAL PANORAMA}

Conforme já apontado no trabalho, a EC 32/2001 demonstrou ter os seguintes objetivos:

(1) Proteger a segurança jurídica, com vedação de determinadas matérias às medidas provisórias, bem como com a proibição da reedição na mesma sessão legislativa e com o regramento da situação jurídica de medidas provisórias revogadas; (2) Restaurar o equilíbrio entre os Poderes, com proibição da edição de medidas provisórias que tratassem da organização do Judiciário e do MP e com a garantia de que o Congresso exerceria suas atribuições, por meio do aumento do prazo e instituição do sobrestamento de pautas; (3) Reduzir a produção de medidas provisórias, tanto por meio da proibição à reedição, quanto com a vedação de um rol de disciplinas que não mais seriam passíveis de regramento por meio de medidas provisórias; (4) Restaurar a participação do Executivo no processo legislativo iniciado por projetos de lei em casos em que não existisse relevância e urgência; (5) Evitar a revogação tácita de medidas provisórias, o que se buscou com o aumento do prazo e com a instituição do sobrestamento de pautas.

A fim de checar se esses objetivos foram atingidos, fizemos uma análise sobre a produção atual de medidas provisórias.

\subsection{Proteção da segurança jurídica}

Uma das principais formas usadas para atingir o objetivo de proteção da segurança jurídica foi a vedação da reedição de medidas provisórias. Como já apontamos, o excesso de reedições fazia com que uma medida provisória vigesse por tempo indeterminado, tanto quanto fosse reeditada, e poderia ser revogada a qualquer 
momento, o que deixava as relações até então regidas por ela em uma área de incerteza.

Esse objetivo pode ser considerado parcialmente atingido, com o fim das reedições e a instituição, no $\S 3^{\circ}$ do art. 62 , de que o Congresso deverá editar decreto legislativo para disciplinar as relações afetadas por medida provisória rejeitada.

Contudo, a própria natureza das medidas provisórias nos coloca em uma situação de insegurança jurídica, em razão da sua vigência imediata, suscetível a revogação ou simples perda de eficácia posterior.

Como se verifica no gráfico 3, a quantidade de medidas provisórias que perderam sua eficácia por decurso do prazo, ou seja, revogadas tacitamente sem serem analisadas no prazo, se mostrou crescente, o que contribui para a insegurança jurídica.

Assim, tivemos certa melhora na situação da insegurança jurídica causada pelas medidas provisórias, como já demonstrado, no entanto, entendemos que não se pode ignorar a insegurança jurídica ainda existente neste âmbito.

\subsection{Restauração do equilíbrio entre os Poderes}

Para checar o objetivo da restauração do equilíbrio entre os poderes, tivemos a análise do sobrestamento de pautas somada à análise comparada da quantidade de leis ordinárias e de medidas provisórias editadas.

Embora se buscasse com o trancamento de pautas restaurar o equilíbrio entre Legislativo e Executivo, concluímos que ele dotou o Presidente da República de ainda mais meios de controle da agenda do Executivo. Como consta no quadro 5, o número de pautas trancadas se mostrou muito alto nos anos analisados, de modo que, em média, $50,81 \%$ das pautas no período estiveram trancadas por medidas provisórias.
No que tange à quantidade de leis ordinárias e de medidas provisórias, demonstradas no quadro 3, notamos que com o fim da reedição, o número de leis ordinárias deixou de ser inferior ao das medidas provisórias. No entanto, apesar dos pressupostos da medida provisória (urgência e relevância), vemos que sua produção ainda está próxima da metade da quantidade de leis ordinárias, o que nos faz, novamente, questionar se esses pressupostos têm sido respeitados.

Por esses motivos, entendemos que este objetivo não foi atingido pela EC 32/2001, pois nossas análises nos levam a concluir que não só o equilíbrio não fora restabelecido, como ficou ainda mais díspar.

\subsection{Redução da produção de medidas provisórias}

As medidas eram editadas e reeditadas inúmeras vezes, o que causava diversos problemas já apontados, de modo que o constituinte reformador buscou na PEC 472/97 mecanismos para reduzir sua produção, dentre os quais a vedação de matérias e à reedição.

De fato, os números foram muito alterados pela vedação da reedição, que fez com que os esses caíssem de cerca de 1000, para cerca de 60. No entanto, ao analisarmos a quantidade de medidas provisórias editadas originariamente, como fizemos no gráfico 1, verificamos que não houve, de fato uma redução na edição.

Assim, também entendemos que esse objetivo foi parcialmente atingido, à luz dessa análise, tendo em vista ter eliminado as reedições, mas não ter reduzido a edição.

\subsection{Restauração da atividade legislativa do Executivo com projetos de lei}

Ao analisar o dossiê da PEC, identificamos uma intenção de restaurar a atividade legislativa 
do Executivo por meio de projetos de lei ordinária, pois o que ocorria era a edição de medidas provisórias em situações que, desprovidas de urgência e relevância, poderiam ser disciplinadas em leis ordinárias.

Para fazer essa análise, temos o quadro 4 e o gráfico 5, que nos demonstram a ausência de impacto da EC 32/2001 na produção de leis de origem do Poder Executivo, inclusive com redução dessa em alguns anos.

Como notamos, a medida provisória ainda é o principal instrumento legislativo utilizado pelo Poder Executivo, de modo que, à luz desses dados, concluímos que este objetivo não foi atingido pela EC.

\subsection{Redução da revogação tácita de medidas provisórias}

Um dos intuitos da EC ao aumentar o prazo de análise das medidas provisórias e instituir o regime de urgência após 45 dias foi reduzir a revogação tácita de medidas provisórias, ou seja, evitar que medidas provisórias vigessem com força de lei sem análise do Congresso e fossem depois revogadas tacitamente. Isso seria também uma forma de proteger a segurança jurídica.

Antes da EC 32/2001, a falta de análise pelo Congresso e as reedições sucessivas andavam juntas. Uma medida não era analisada no prazo, era reeditada, e assim sucessivamente.

Para checar esse objetivo temos os dados do quadro 2 e o gráfico 3. Como verificamos, não tivemos uma redução, mas sim um aumento da revogação tácita de medidas provisórias. Assim, concluímos que este objetivo também não foi atingido pela EC.

\section{CONCLUSÃO}

O objetivo desta pesquisa consistiu em avaliar a eficácia da Emenda Constitucional
32/2001. Para conseguir atingi-lo, traçamos um plano de trabalho que nos permitiu compreender o instituto das medidas provisórias e sua inserção em nosso ordenamento jurídico, e observar empiricamente a realidade criada pela EC em questão.

Apesar de ainda ser a base da atual Organização dos Poderes, a teoria clássica de Montesquieu exige hoje outra interpretação em razão das características do atual Estado, em que se demanda dele uma atuação por meio de políticas públicas. Um dos instrumentos existentes para possibilitar tal atuação é a medida provisória, que seria responsável por garantir governabilidade e ser um mecanismo rápido para atuar.

No entanto, sua instituição deu ao Presidente da República um vasto poder de controlar a agenda do Poder Legislativo, o que resultou no desenvolvimento de estudos que concluíram que nosso governo seria um "Presidencialismo de Coalizão", resultante da inédita combinação das medidas provisórias com o presidencialismo.

Contudo, as medidas provisórias, que deveriam ser provisórias, começaram a viger por tempo indeterminado em razão das sucessivas reedições, o que abalou a Separação de Poderes, a segurança jurídica e levou à insatisfação do Congresso.

Nesse contexto surgiram várias propostas de Emenda Constitucional com o intuito de solucionar os problemas causados pelas medidas provisórias, dentre as quais a PEC 472/1997 da qual resultou a EC 32/2001. Nosso propósito nesse estudo foi avaliar a eficácia da EC 32/2001 e para isso usamos da análise documental em busca de seus objetivos, para que esses pudessem posteriormente ser verificados.

Deste modo, solicitamos à Câmara dos Deputados o dossiê digitalizado da PEC 472/97, e foram analisados: o texto inicial, a justificativa, os 
pareceres das Comissões, algumas discussões bem como o texto final da Emenda Constitucional.

Nosso estudo nos permitiu obter como objetivos da EC 32/2001: reduzir os abalos à segurança jurídica; limitar a produção de medidas provisórias; restaurar o equilíbrio entre os Poderes; dar fim à reedição; restaurar a atuação do Executivo na legislação pela via ordinária; evitar a revogação tácita de medidas provisórias.

Assim, para que pudéssemos verificar os objetivos destacados, partimos à análise empírica, em busca de dados que estivessem relacionados a eles. Obtivemos então dados relativos à produção de medidas provisórias antes e depois da EC; dados sobre a produção legislativa do Executivo como um todo; e dados sobre o trancamento de pautas por medidas provisórias.

Observamos que apesar de ter-se encerrado a prática das reedições, a estipulação de limites materiais não fez com que reduzisse a edição de medidas provisórias, que em alguns anos foi até mesmo superior ao que era antes da EC. Notamos também que, comparada à produção de leis ordinárias, a de medidas provisórias deixou de ser superior àquela, graças ao fim da reedição.

Os dados nos demonstraram ainda que a produção legislativa ordinária do Executivo não aumentou após a EC 32/2001, e em alguns anos foi inferior ao que era antes. Já no que diz respeito ao trancamento de pautas, foi possível observar que quantidade muito alta de pautas é trancada por medidas provisórias, o que demonstra grande controle da agenda do Legislativo pelo Executivo.

Posterior à coleta de dados, traçamos uma verificação de cada objetivo levantado da EC, e concluímos que apenas foram parcialmente atingidos os relativos à redução da produção de medidas provisórias (atingido graças ao fim da reedição, mas parcialmente, pois o número de medidas provisórias editadas originariamente não sofreu notável redução); e à proteção da segurança jurídica (também atingido em razão do fim da reedição, mas parcialmente, pois a insegurança jurídica é inerente à natureza das medidas provisórias).

Quanto aos demais objetivos: não se atingiu o reequilíbrio entre Executivo e Legislativo (na verdade o desequilíbrio até mesmo se agravou com o sobrestamento de pautas); tampouco aumentou a atuação do Executivo na legislação ordinária (verificamos que essa não sofreu alteração, tendo sido inferior em alguns anos); e também não se reduziu a revogação tácita de medidas provisórias (pelo contrário, aumentou).

Como resultado dessa verificação, e sob esse ângulo de análise, concluímos que a EC $32 / 2001$ foi parcialmente ineficaz, pois não atingiu a maioria de seus objetivos. Importante destacar que não concluímos por sua ineficácia total, pois o papel que desempenhou ao encerrar a prática das reedições foi de grande significância, não podendo ser desconsiderado nessa análise.

Por conseguinte, notamos que ainda existem diversos problemas que envolvem as medidas provisórias, tal como o desequilíbrio causado pelo trancamento de pautas entre Legislativo e Executivo. Como vimos, o trancamento é a regra, e não a exceção, o que faz com que o Presidente tenha hoje tanta capacidade de controlar a agenda do Congresso quanto tinha antes da EC 32/2001.

Grande parte das medidas provisórias é editada sem atender aos pressupostos constitucionais e o controle jurisdicional dessa situação ocorre apenas excepcionalmente, em raríssimos casos. Isso nos remete à reduzida atuação do Executivo na legislação por meio de leis ordinárias, pois como é quase nulo o controle dos pressupostos da medida provisória, o Presidente da República tem "carta branca” para editá-las (mesmo quando não cabível) de modo muito mais célere, o que torna desinteressante o uso do projeto de lei ordinária. 
Portanto, concluímos ser necessário um novo regramento capaz de garantir que as medidas provisórias sejam utilizadas apenas em situações urgentes e relevantes, como prevê a Constituição, o que reduziria grande parte dos problemas observados. Outra mudança que acreditamos ser necessária é o sobrestamento de pautas pelas medidas provisórias, que tem prejudicado as relações Executivo-Legislativo.

\section{REFERÊNCIAS}

ABRANCHES, Sergio. Presidencialismo de coalizão: o dilema institucional brasileiro. Dados: Revista de Ciências Sociais, Rio de Janeiro, v. 31, n. 1, p. 3-55, 1988.

AMARAL JÚNIOR, José Levi Mello do. Medida provisória e sua conversão em lei: a Emenda Constitucional no. 32 e o papel do Congresso Nacional. São Paulo: Revista dos Tribunais, 2004.

BRASIL. Constituição (1988). Constituição da República Federativa do Brasil. Altera dispositivos dos arts. 48, 57, 61, 62, 64, 66, 84, 88 e 246 da Constituição Federal, e dá outras providências. Emenda Constitucional n. 000032 de 11 de setembro de 2001. Diário Oficial da União: República Federativa do Brasil: Poder Legislativo, Brasília, 12 set. 2001. Seção 1, p. 1. Disponível em: $<$ http://www2.camara.leg.br/legin/fed/emecon/2001/emendaconstitucional-32-11-setembro-2001395730-publicacaooriginal-1-pl.html>. Acesso em: 20 jan. 2016.

. Constituição (1988). Constituição da República Federativa do Brasil. Diário Oficial da União: República Federativa do Brasil: Poder Legislativo, Brasília, 5 out. 1988. Disponível em: <http://www.planalto.gov.br/ccivil_03/constituicao/constituicaocompilado.html>. Acesso em: 06 mai. 2018.

. Constituição (1967) Constituição da República Federativa do Brasil de 1967. Diário Oficial da União: República Federativa do Brasil: Poder Legislativo, Brasília, 24 jan. 1967. Disponível em: <http://www.planalto.gov.br/ccivil_03/constituicao/constituicao67.htm>.

Acesso em: 06 mai. 2018.

. Câmara dos Deputados. Projeto de Emenda Constitucional nº472, de 15 de maio de 1997. Dispõe sobre a alteração dos dispositivos dos arts. 48, 62 e 84 da Constituição Federal, e dá outras providências. Convertida na EC 32/2001. Diário da Câmara dos Deputados, Brasília, ano LII, nº 139, 12 ago. $1997 . \quad$ Disponível em: <http://imagem.camara.gov.br/Imagem/d/pdf/DCD12AGO1997.pdf\#page=247>. Acesso em: 05 abr. 2017.

. Câmara dos Deputados. Dossiê digitalizado da PEC 472/1997. Brasília: 2001. Solicitado em: < http://www.camara.gov.br/proposicoesWeb/fichadetramitacao?idProposicao $=14784>$. Acesso em: 04 abr. 2017.

CRUZ, Fabrício Bittencourt da. Medida Provisória: dogmas e realidade. São Paulo: Ed. Revista dos Tribunais, 2017. 
EUROPEAN Comission. DG Market Guide to Evaluating Legislation. Brussels: 2008. Disponível em: <http://ec.europa.eu/dgs/internal_market/docs/evaluation/evaluation_guide. pdf > . Acesso em: 09 abr. 2015.

FIGUEIREDO, Argelina C. Executivo e Legislativo na nova ordem constitucional / Argelina Cheibub Figueiredo e Fernando Limongi. 2a ed. Rio de Janeiro: Editora FGV, 2001.

LIMONGI, Fernando; FIGUEIREDO, Argelina. Bases institucionais do presidencialismo de coalizão. Lua Nova, São Paulo, n. 44, p. 81-106, 1999. Disponível em: <http://www.scielo.br/scielo.php?script=sci_arttext\&pid=S010264451998000200005\&lng=en\&nrm= iso>. Acesso em: 20 ago. 2016.

MONTESQUIEU, Charles de Secondat, Baron de, 1689-1755. O espírito das leis: apresentação Renato Janine Ribeiro; tradução Cristina Murachco. 3a ed. São Paulo: Martins Fontes, 2005.

OLIVEIRA, Magali Carvalho Alves de. Medidas provisórias e a relação Executivo x Legislativo: uma visão do sobrestamento de pauta. Monografia (Especialização em Instituições e Processos Políticos do Legislativo) - Centro de Formação, Treinamento e Aperfeiçoamento, Brasília, DF, 2009.

SALINAS, Natasha Schmitt Caccia. Avaliação legislativa no Brasil: Um estudo de caso sobre as normas de controle das transferências voluntárias de recursos públicos para entidades do terceiro setor. Monografia (Mestrado em Filosofia e Teoria Geral do Direito) - Faculdade de Direito da Universidade de São Paulo, São Paulo, SP, 2008.

SILVA, Christiane Satiê Moritsugu. Os motivos políticos e jurídicos que ensejaram as mudanças na tramitação das medidas provisórias. Monografia (Especialização em Processo Legislativo) - Centro de Formação, Treinamento e Aperfeiçoamento, Brasília, DF, 2013.

SOUZA, Carlos Aurélio Mota de (Coord.). Medidas provisórias e segurança jurídica. São Paulo: Juarez de Oliveira, 2003. 
